\title{
Asymptomatic Hyperammonemia in Low Birthweight Infants
}

\author{
MARK L. BATSHAW ${ }^{(35)}$ AND SAUL W. BRUSILOW
}

John F. Kennedy Institute and the Department of Pediatrics, The Johns Hopkins University School of Medicine, Baltimore, Maryland, USA

\begin{abstract}
Summary
At 0-3 days of age the plasma ammonium concentration in full term appropriate for gestational age (AGA) infants was (mean \pm SEM) $27.5 \pm 0.5 \mu \mathrm{M}$; a value similar.to that reported in adults. Ammonium levels in low birthweight AGA and SGA groups were $47.0 \pm 2.0 \mu \mathrm{M}$ and $45.1 \pm 3.3 \mu \mathrm{M}$ respectively; significantly elevated $(P<0.001)$ as compared to the full term group. These increased ammonium levels persisted at 3-5 weeks of age. Associated with the hyperammonemia was a significant $(P<0.01)$ decrease in plasma $\alpha$-ketoglutarate concentration: $11.8 \pm 1.0 \mu \mathrm{M}$, in the low birthweight AGA as compared to $20.7 \pm 0.6 \mu \mathrm{M}$ in the full term AGA infants. There was an inverse linear correlation between plasma concentrations of ammonium and $\alpha$-ketoglutarate $r=-0.86, P<0.001$. Urinary orotate excretion was significantly elevated $(P<0.05)$ in low birthweight AGA infants. There was no difference in the plasma concentrations of glutamine, glutamate, or alanine among the various groups. Hyperammonemia was not associated with neurologic dysfunction.
\end{abstract}

\section{Speculation}

There is a greater accumulation of ammonium in low birthweight as compared to full term infants. This may be a consequence of a developmental delay of one or more of the enzymes required for urea synthesis. Alternatively, the hyperammonemia may be related to arginine and/or ornithine diversion out of the cycle and incomplete repletion of ornithine from glutamate via the $\Delta^{\prime}$-pyrroline-5-carboxylate pathway.

Hyperammonemia in childhood is most commonly seen in liver disease, parenteral nutrition, Reye's syndrome, and congenital urea cycle enzyme defects. We have noted hyperammonemia in low birthweight infants and present here a study of changes in plasma levels of ammonium and other substrates related to ammonium disposition during the first 2 months of life in full term, low birthweight SGA, and low birthweight AGA infants.

\section{MATERIALS AND METHODS}

Newborn infants admitted to the Infant Special Care Unit and the Newborn Nursery at Johns Hopkins Hospital comprised the study groups. None of the infants had pre-existing liver disease or received parenteral nutrition. The study group included 52 full term AGA infants, 9 low birthweight SGA infants, and 27 low birthweight AGA infants. Low birthweight is defined as a birthweight below $2500 \mathrm{~g}$ as recommended by the WHO (29). SGA is defined as a birth weight less than the tenth percentile for gestational age (9), using the Colorado indices (17).

Informed consent was obtained for the study, which was approved by the Joint Committee on Clinical Investigation. Plasma levels of ammonium, glutamine, alanine, and glutamate were measured once or twice a week on capillary blood during the first 2 months of life. Plasma $\alpha$-ketoglutarate concentration and urinary orotate excretion were also measured at $0-3$ days of age in 30 infants. Plasma ammonium determinations were performed within 30 min of blood drawing using a cation exchange resin, as previously described (3). The normal adult range is $15-33 \mu \mathrm{M}$. Glutamine (18), glutamate (4), alanine (30), and $\alpha$-ketoglutarate (16) were measured by modifications of enzymatic fluorometric techniques, allowing capillary plasma to be used. Urinary orotate was measured by the method of Goldstein et al. (11). A neurologic examination as described by Prechtl and Beintema (20) was performed on the low birthweight infants at $0-3$ days of age.

\section{RESULTS}

The full term group consisted of 25 males ( 22 were black) and 27 females ( 25 were black); the low birthweight groups consisted of 14 males (11 were black) and 22 females (20 were black). Birthweights of the groups were (mean \pm SEM): full term 3261 $\pm 59 \mathrm{~g}$, low birthweight SGA $1848 \pm 185 \mathrm{~g}$, and low birthweight AGA $1963 \pm 79 \mathrm{~g}$. Gestational age in the groups were (mean \pm SD): full term AGA $39 \pm 1.5$ weeks, low birthweight SGA $37 \pm 3$ weeks and low birthweight AGA $33 \pm 2.5$ weeks. All infants received a proprietary milk formula (Similac) containing $1.5 \mathrm{~g}$ protein $/ 100 \mathrm{ml}, 18$ parts bovine whey protein to 82 parts bovine caseins. Mean protein intake was similar in all groups at $3-5$ weeks of age $(3.0 \mathrm{~g} / \mathrm{kg} /$ day $)$ and was higher in the full term group during the first 3 days of life ( 1.7 compared to $1.2 \mathrm{~g} / \mathrm{kg} /$ day). At 0-3 days of age, mean daily caloric intake was $70 \mathrm{cal} /$ $\mathrm{kg}$ in the low birthweight infants and $60 \mathrm{cal} / \mathrm{kg}$ in the full term infants. From 3-5 weeks' of age, the mean caloric intake was $140 \mathrm{cal} / \mathrm{kg}$ and $120 \mathrm{cal} / \mathrm{kg}$ in the low birthweight and full term groups, respectively.

Table 1 lists plasma ammonium levels during the first 2 months of life in the three groups: full term, low birthweight SGA, and low birthweight AGA infants. The full term group comprised 41 delivered spontaneously and 11 by cesarean section. At 0-3 days of age, there was no significant difference in plasma ammonium levels between full term infants delivered vaginally and by cesarean section (mean \pm SEM): $27.2 \pm 0.6$ and $28.8 \pm 1.0 \mu \mathrm{M}$, respectively. Similar levels were obtained at 3-5 weeks of age.

Plasma ammonium levels in low birthweight AGA and low birthweight SGA groups were $47.0 \pm 2.0 \mu \mathrm{M}$ and $45.1 \pm 3.3$ $\mu \mathrm{M}$, respectively, at $0-3$ days of age. Of the 36 low birthweight infants, four had plasma ammonium concentrations below 33 $\mu \mathrm{M}$ (Fig. 1) and were not followed. The remaining infants were followed until they were 6-8 weeks of age. The significant elevation in ammonium levels persisted in the low birthweight groups at 3-5 weeks of age with levels of $42.9 \pm 1.0 \mu \mathrm{M}$ in the SGA groups and $47.7 \pm 3.0 \mu \mathrm{M}$ in the AGA group. When the infants reached full term by weight $(2500 \mathrm{~g})$ or by gestational age (38 weeks) they were still hyperammonemic (mean \pm SEM): $40.0 \pm 2.9 \mu \mathrm{M}$ and $47.2 \pm 3.3 \mu \mathrm{M}$, respectively. At 6- 
Table 1. Concentrations of plasma ammonium in full term, low birth weight $S G A$ and low birthweight $A G A$ infants during the first 2 months of life

\begin{tabular}{lccc}
\hline & $0-3$ days & $3-5$ weeks & 6-8 weeks \\
\hline Full term & $27.5 \pm 0.5$ & $25.9 \pm 3.1$ & \\
& $\mathrm{n}=52$ & $\mathrm{n}=8$ \\
Low birthweight & $45.1 \pm 3.3^{1}$ & $42.9 \pm 1^{2}$ & $29.8 \pm 1.2$ \\
SGA birthweight & $\mathrm{n}=9$ & $\mathrm{n}=8$ & $\mathrm{n}=9$ \\
Low & $47.0 \pm 2.0^{1}$ & $47.7 \pm 3.0^{2}$ & $26.9 \pm 1.6$ \\
AGA & $\mathrm{n}=27$ & $\mathrm{n}=15$ & $\mathrm{n}=9$ \\
\hline
\end{tabular}

${ }^{1} P<0.001$ compared to full term.

${ }^{2} P<0.005$ compared to full term.

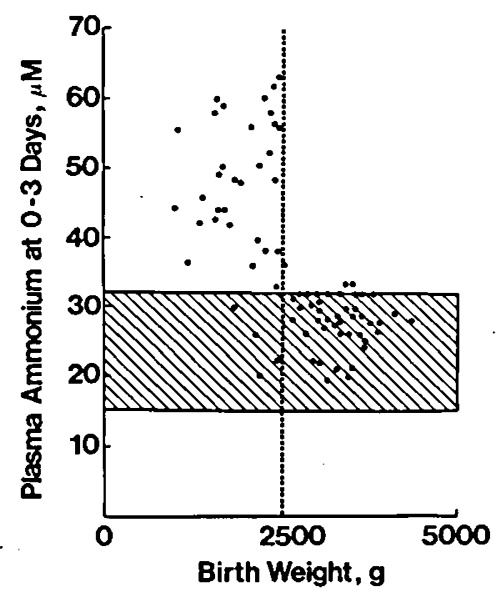

Fig. 1. The relationship between birthweight and plasma concentration of ammonium at $0-3$ days of life $(n=80)$. Normal range of plasma ammonium in adults is indicated by cross-hatching.

8 weeks of postnatal age, plasma ammonium levels were normal in both low birthweight AGA and low birthweight SGA groups: $26.9 \pm 1.6$ and $29.8 \pm 1.2 \mu \mathrm{M}$, respectively. No statistically significant relationships were noted when plasma ammonium concentration was correlated with gestational age below 40 weeks, sex, race, protein intake, or plasma glutamine level. The distribution of plasma ammonium levels at 0-3 days as related to birthweight is shown in Figure 1. At birthweights below 2500 $\mathrm{g}$ more than $85 \%$ of the infants were hyperammonemic; at birthweights above $2500 \mathrm{~g}$, virtually all infants had normal ammonium levels.

Plasma $\alpha$-ketoglutarate concentration was measured because of its relationship to ammonium metabolism. We found a significant $(P<0.01)$ decrease in plasma $\alpha$-ketoglutarate concentration, $11.8 \pm 1.0 \mu \mathrm{M}$, in the low birthweight AGA as compared to $20.7 \pm 0.6 \mu \mathrm{M}$ in the full term infants (2). Using data from the full term and low birthweight AGA infants, we found an inverse linear correlation between plasma concentration of ammonium and $\alpha$-ketoglutarate $(r=-0.86, P<0.001)$ (Fig. 2).

Urinary orotic acid excretion was measured because it has been described as being increased in urea cycle enzyme defects other than carbamylphosphate synthetase deficiency. We found a small but significant $(P<0.05)$ increase in orotic acid excretion in low birthweight AGA group as compared to the full term group (Table 2 ). There was no difference in the plasma concentrations of glutamine, glutamate, or alanine among the various groups (Table 3). On neurologic examination, the level of alertness, symmetry of movement, deep tendon reflexes, and primitive reflexes were not abnormal in the hyperammonemic infants.

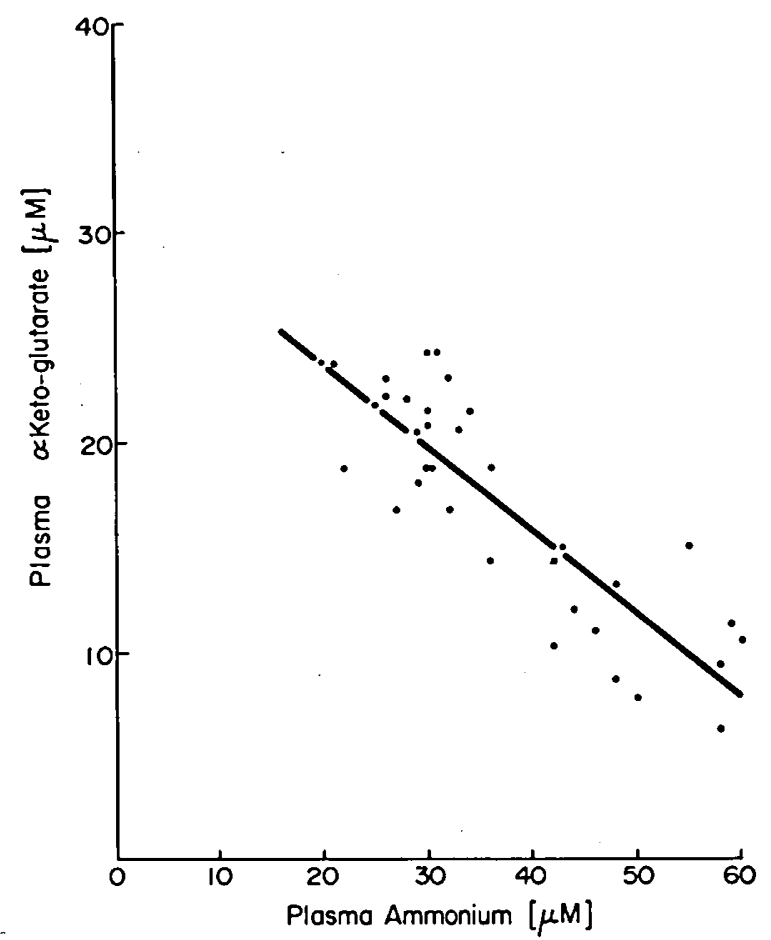

Fig. 2. The relationship between plasma ammonium and $\alpha$-ketoglutarate levels in low birthweight AGA and fullterm infants $(\mathrm{n}=35, r=$ $-0.86, y=-0.39 x+31.6)$.

Table 2. Plasma $\alpha$-ketoglutarate concentration and urinary orotate excretion in full term and low birthweight infants at 0-3 days of age

\begin{tabular}{lcc}
\hline & $\begin{array}{c}\alpha \text {-Ketoglutarate, } \\
\mu \mathrm{M} \pm \mathrm{SEM}\end{array}$ & $\begin{array}{c}\text { Orotic acid, } \mu \mathrm{g} / \mathrm{mg} \\
\text { creatinine } \pm \mathrm{SEM}\end{array}$ \\
\hline Full term & $20.7 \pm 0.6$ & $4.3 \pm 0.9$ \\
& $<\mathrm{n}=17\rangle$ & $\mathrm{n}=14$ \\
Low birthweight AGA & $11.8 \pm 1.0^{1}$ & $9.3 \pm 2.0^{2}$ \\
& $\mathrm{n}=13$ & $\mathrm{n}=18$ \\
Normal $(2,11)$ & $18-25$ & $0-8.7^{3}$ \\
\hline
\end{tabular}

${ }^{1} P<0.01$ compared to full term.

${ }^{2} P<0.05$ compared to full term.

${ }^{3}$ Micrograms per milligram.

\section{DISCUSSION}

\section{PLASMA AMMONIUM LEVELS IN NEONATES}

Clemmens (7) measured whole blood ammonia in 46 infants between $30 \mathrm{~min}$ and 36 days of age, using the alkali distillation method of Seligson (26), and found no difference between low birthweight and full term infants, range $7-116 \mu \mathrm{M}$. This test is nonspecific for ammonia as it also measures other alkali labile nitrogen (24): the range of normal is $50-100 \mu \mathrm{M}$, whereas the range of normal for the true blood ammonium (as measured by cation-exchange resin or ammonium electrode) is $15-30 \mu \mathrm{M}$ (21).

Rubaltelli (25), using a cation-exchange method, found that full term SGA infants, less than 5 days of age, had higher plasma ammonium levels $(48 \pm 10 \mu \mathrm{M})$ than did full term AGA infants $(35 \pm 5 \mu \mathrm{M})$. Räihä et al. (22) found plasma ammonium levels of low birthweight infants less than 6 weeks of age to vary between 60-90 $\mu \mathrm{M}$ when measured with an ammonium electrode. They commented that these levels were not abnormal. Yet when Proelss et al. (21), who also used an ammonium 
Table 3. Concentrations of plasma glutamine, alanine, and glutamate in study patients during first 5 weeks of life ${ }^{1}$

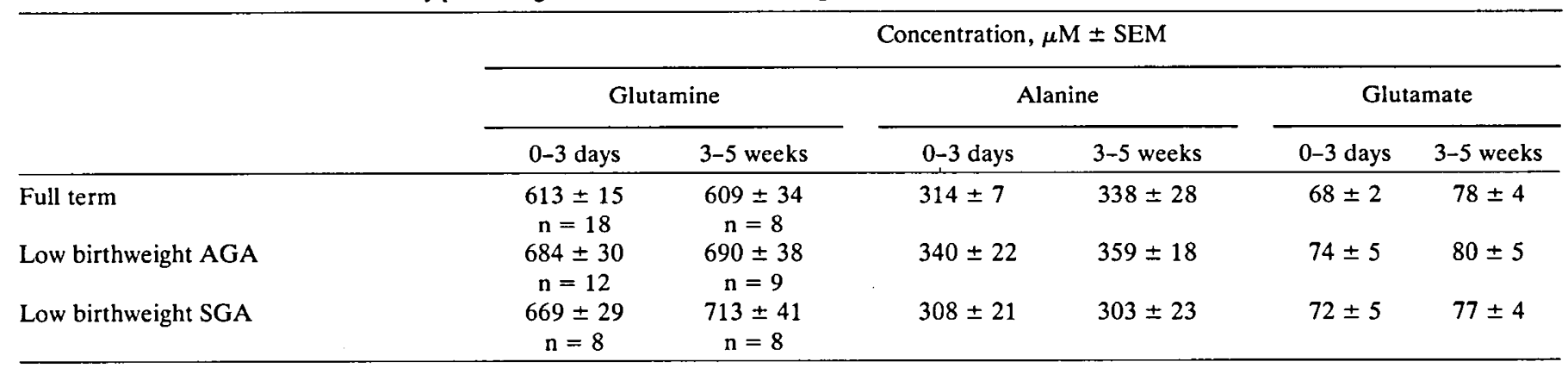

${ }^{1}$ Normal ranges: glutamine, 342-1046; alanine, 177-476; glutamate, 16-64.

electrode, compared plasma ammonium levels measured by the electrode and by an ion-exchange technique, they found a correlation coefficient of 0.994 and an upper limit of normal of $30 \mu \mathrm{M}$. Oberholzer et al. (19) showed significant differences in resin plasma ammonium levels of full term infants $0-3$ days of age as compared to $1-12$ weeks of age (mean \pm SD): $86 \pm 20$ compared to $25 \pm 5 \mu \mathrm{M}$.

Although the reasons for these discrepancies are not apparent, they may relate in part to the care needed in obtaining the blood sample and the rapidity of performing the test. In our study, free-flowing capillary blood was collected in heparinized tubes and immediately placed on ice. The cation-exchange assay was performed less than $0.5 \mathrm{hr}$ after obtaining blood. Using this method, we observed persistent hyperammonemia $(37-76 \mu \mathrm{M})$ for 2 months postnatally in almost all low birthweight infants tested, whereas it was not found in infants with birthweights over $2500 \mathrm{~g}$. Hyperammonemia was frequently associated with an elevation in urinary orotate excretion and was always associated with a decrease in the plasma concentration of $\alpha$-ketoglutarate. No intergroups differences were noted in plasma concentrations of glutamine, glutamate, and alanine.

\section{AMMONIUM ACCUMULATION}

Although the mechanism of hyperammonemia in low birthweight infants is unclear, it could result from portal-systemic shunting, urea cycle enzyme deficiency, or ornithine or arginine depletion. Little is known about the possibility of portal-systemic shunting from persistence of the patent ductus venosus in low birthweight infants. Portal-systemic shunting in adults results in hyperammonemia associated with normal or increased plasma levels of $\alpha$-ketoglutarate $(8,15)$. In the low birthweight infants, $\alpha$-ketoglutarate levels were found to be low, suggesting that portal-systemic shunting may not be responsible for the hyperammonemia.

The substrates, enzymes and possible regulatory steps in the synthesis of urea are depicted in Figure 3. Also included in the figure are the pathways for depletion and repletion of the cycle intermediates.

Räihä (23) found that all the urea cycle enzymes had sufficient in vitro activity by 28 weeks of gestation to preclude accumulation of substrates or significantly retard urea synthesis. However, it is possible that in vivo activity in low birthweight infants may not be sufficient to cope with high protein intakes. One might then have expected an inverse correlation between gestational age and plasma ammonium levels. This was not observed. We also did not find a direct relationship between ammonium and other labile nitrogen components, glutamine, glutamate, and alanine as we have observed in patients with urea cycle defects. Acetylglutamate synthetase activity has not been evaluated; a defect in this enzyme might result in impaired carbamylphosphate synthetase activity.

The finding of an increase in orotic acid excretion suggests accumulation of carbamylphosphate as a consequence of low

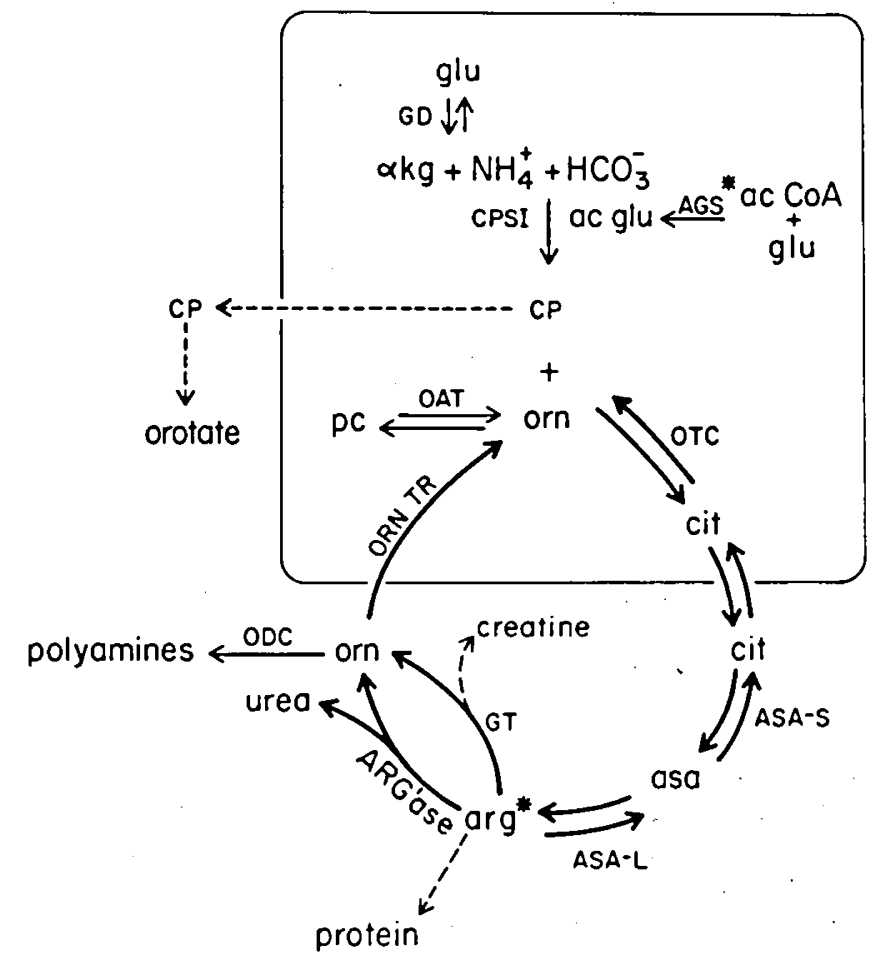

Fig. 3. The enzymes and substrates related to ammonium disposition and urea synthesis. GD: glutamate dehydrogenase; CPSI: carbamylphosphate synthetase I; Ac glu: acetylglutamate; AGS: acetylglutamate synthetase; cp: carbamylphosphate; OTC: ornithine transcarbamylase, ASA-S: argininosuccinic acid synthetase; ASA-L: ASA-lyase; ODC: ornithine decarboxylase; ORN TR: ornithine translocation; OAT: ornithine $\delta$-amino transferase; pc: $\Delta^{\mathbf{1}}$-pyrroline-5-carboxylate; GT: glycine transamidinase. Reactions enclosed in the box are mitochondrial. Enzymes are denoted by capital letters, substrates by lower case letters. ${ }^{*}$ : Arginine is an activator of acetylglutamate synthetase (28).

intramitochondrial levels of ornithine. This could result from defective ornithine translocation (10) or a developmental delay in ornithine synthesis from substrates other than arginine; glutamate, proline, or $\Delta^{1}$-pyrroline-5-carboxylate.

That preterm infants may have some inadequacy in the de novo synthesis of $\Delta^{1}$-pyrroline 5-carboxylate or ornithine may be adduced from the findings of Snyderman (27) that preterm infants become hypoargininemic on marginal protein intakes. Furthermore, the requirement of preterm infants for supplemental ornithine or arginine to prevent hyperammonemia while they are receiving total parenteral nutrition (13) also suggests a limited ability of the preterm infant to synthesize sufficient ornithine for the formation of protein and polyamines (only catalytic amounts are needed for synthesis of creatine and urea). 


\section{$\alpha$-KETOGLUTARATE DEPLETION}

The inverse correlation between plasma ammonium and $\alpha$ ketoglutarate (Fig. 2) is consistent with the evidence that ammonium alters the redox state of liver mitochondria in the direction of oxidation, accompanied by a decrease in mitochondrial levels of $\alpha$-ketoglutarate $(5,28)$. Studies of the brain response to hyperammonemia also suggest that as the mitochondrial $\mathrm{NAD}^{+}: \mathrm{NADH}$ ratio increases $(12,31), \alpha$-ketoglutarate content may decrease (14). The significant negative correlation we have found between plasma levels of ammonium and $\alpha$ ketoglutarate is compatible with the hypothesis that the mitochondria are more oxidized in the hyperammonemic state. We have also noted an inverse relationship between plasma concentrations of ammonium and $\alpha$-ketoglutarate in patients with urea cycle enzyme deficiencies (6). Recently Krebs (32) suggested that in vitro, gluconeogenesis may be impaired by high concentration of ammonium. The finding of hyperammonemia in SGA infants who are known to have impaired gluconeogenesis suggests that there may be a relationship between the two, perhaps as a result of decreased formation of glyceraldehyde-3-phosphate secondary to NADH depletion.

The present study shows that there is greater ammonium accumulation in low birthweight as compared to full term AGA infants. The mechanisms responsible are unknown but may involve one or more of the enzymes responsible for urea synthesis. Alternatively, the hyperammonemia may be related to arginine and/or ornithine diversion out of the cycle and incomplete repletion of ornithine from glutamate via the $\Delta^{1}$ pyrroline-5-carboxylate pathway. There were no acute neurologic abnormalities associated with the hyperammonemia, but whether hyperammonemia places the low birthweight infant at risk for future neurodevelopmental problems remains to be determined.

\section{REFERENCES AND NOTES}

1. Abitbol, C. L., Feldman, D. B., Ahmann, P., and Rudman, D.: Plasma amino acid patterns during supplemental intravenous nutrition of low birth weight infants: J. Pediat., 86: 766 (1975).

2. Alleyne, G. A. O., and Scullard, G. H.: Blood keto-acids in malnutrition. Amer. J. Clin. Nutr., 22: 1139 (1969)

3. Batshaw, M., Brusilow, S., and Walser, M.: Treatment of carbamyl phosphate synthetase deficiency with keto-analogues of essential amino acids. New Engl. J. Med., 292: 1085 (1975).

4. Bernt, E. and Bergmeyer, H. U.: Determination of L-glutamate. In: H. U. Bergmeyer: Methods of Enzymatic Analysis, p. 1704 (Academic Press, New York, 1974).

5. Brosnan, J. T., and Williamson, D. H.: Mechanisms for the formation of alanine and aspartate on rat liver in vivo after administration of ammonium chloride. Biochem. J., 138: 453 (1974).

6. Brusilow, S., Batshaw, M., Walser, M.: The mechanism of hyperammonemia in citrullinemia. Pediat. Res.

7. Clemmens, R. L., Schear, S. B. and Bessman, S. P.: Ammonia in the blood of newborn infants. Pediatrics 21: 22 (1958).

8: Dawson, A. M., De Groote, J., Rosenthal, W. S., and Sherlock, S.: Blood pyruvic acid and alpha-ketoglutaric-acid levels in liver disease and hepatic coma. Lancet, 1: 392 (1957).

9. Dubowitz, L. M. S., Dubowitz, V., and Goldberg, C.: Clinical assessment of gestational age in the newborn infant. J. Pediat., $77: 1$ (1970).

10. Gamble, J. G., and Lehninger, A. L.: Transport of ornithine and citrulline across the mitochondrial membrane. J. Biol. Chem., 248: 610 (1973).
11. Goldstein, A. S., Hoogenraad, N. J., Johnson, J. D., et al.: Metabolic and genetic studies of a family with ornithine transcarbamylase deficiency. Pediat. Res., 8: 5 (1974).

12. Hawkins, R. A., Miller, A. L., Nielsen, R. C., and Veech, R. L.: The acute action of ammonia on rat brain metabolism in vivo. Biochem. J., 134: 1001 (1973).

13. Heird, W. C., Nicholson, J. F., Driscoll, J. M., Schullinger, J. N., and Winters, R. W.: Hyperammonemia resulting from intravenous alimentation using a mixture of synthetic Lramino acids: A preliminary report. J: Pediat:, 81: $162(1972)$.

14. Hindfelt, B.: The effect of sustained hyperammonemia upon the metabolic state of the brain. Scand. J. Clin. Lab. Invest., 30: 245 (1972).

15. Laudahn, G.: Fermentaktivitaten und konzentration von stoffwechselz-wischenprodukten im blut bei leber und herzkrankheiten. Klin. Woch., 37: 850 (1959).

16. Lowry, O. H. and Passonneau, J. V.: A Flexible System of Enzymatic Analysis, p. 82 (Academic Press, New York, 1972).

17. Lubchenco, L. O., Hansman, C., Dressler, M., and Boyd, E.: Intrauterine growth as estimated from liveborn birth-weight data at 24 to 42 weeks of gestation. Pediatrics 32: 793 (1963).

18. Lund, P.: Determination of glutamine with glutaminase and glutamate dehydrogenase. In: H. U. Bergmeyer: Methods of Enzymatic Analysis, 2nd English ed., p. 1719 (Academic Press, New York 1974).

19. Oberholzer, V. G., Schwarz, K. B., Smith, C. H., et al.: Microscale modification of a cation exchange column procedure for plasma ammonia. Clin. Chem., 22: 1976 (1976).

20. Prechtl, H., and Beintema, D.: The neurological examination of the full-term newborn infant. In: Little Club Clinic in Developmental Medicine, No. 12 (Heinemann Ltd., London, 1964).

21. Proelss, H. F., and Wright, B. W.: Rapid determinants of $\mathrm{NH}_{3}$ in a perchloric acid supernate from blood by use of an ammonia-specific electrode. Clin. Chem., 19: 1162 (1973).

22. Räihä, N. C. R., Heinonen, K., Rassin, D. K., and Gaull, G. E.: Milk protein quantity and quality in low-birth weight infants: I. Metabolic responses and effects on growth. Pediatrics, 57: 659 (1976)

23. Räihä, N. C. R., and Suihkonen, J.: Development of urea synthesizing enzymes in human liver. Acta Paediat. Scand., 57: 121 (1968).

24. Reif, A.: Blood ammonia. Anal. Biochem., 1: 351 (1960)

25. Rubaltelli, F. F., Formentin, P. A., and Tatô, L.: Ammonia nitrogen, urea and uric acid blood levels in normal and hypodystrophic newborns. Biol. Neonate, 15: 129 (1970).

26. Seligson, D., and Hirahara, K.: The measurement of ammonia in whole blood, erythrocytes and plasma. J. Lab. Clin. Med., 49: 962 (1957).

27. Snyderman, S. E., Holt, L. E., Norton, P. M., and Phansalker, S. V.: Protein requirement of the premature infant. II. Influence of protein intake on free amino acid content of plasma and red blood cells. Amer. J. Clin. Nutr., 23: 890 (1970).

28. Tatibana, M., Shigesada, K. and Mori, M.: Acetylglutamate synthetase. In: S. Grisolia, R. Baguena, and F. Mayor: The Urea Cycle, p. 95 (Wiley \& Sons, New York, 1976)

29. WHO Expert Committee on Maternity and Child Health: Public health aspects of low birthweight. Tech. Rep. Series no. $217,1961$.

30. Williamson, D. H.: Determination of L-alanine with alanine dehydrogenase. In: H. U. Bergmeyer: Methods of Enzymic Analysis, 2nd English ed., p. 678 (Academic Press, New York, 1974)

31. Williamson, D. H., Lund, P. and Krebs, H. A.: The redox state of free nicotinamide-adenine dinucleotide in the cytoplasm and mitochondria of rat liver. Biochem. J., 103: 514 (1967)

32. Krebs, H. A., Lund, P., and Stubbs, M.: Interrelationships between gluconeogenesis and urea synthesis. In: R. W. Hanson and M. A. Mehlman: Gluconeogenesis: Its Regulation in Mammalian Species, p. 269 (John Wiley \& Sons, New York, 1976)

33. We are indebted to Ellen Gordes for her technical assistance.

34. This research was supported by USPHS Research Grants AM 18020, HDAM 11134, and Clinical Center Grant AM 12934 and funds from the Kerr Foundation.

35. Requests for reprints should be addressed to: M. Batshaw, M.D., The John F. Kennedy Institute, 707 N. Broadway, Baltimore, MD 21205 (USA).

36. Received for publication March 23, 1977.

37. Accepted for publication June 28, 1977. 